\title{
Do Children With Different Attachment Type Perceive Different Parental Rearing?
}

\author{
Sakineh Mofrad*, Rohani Abdullah** and Bahaman Abu Samah*** \\ Department of Human Development \& Family Studies, Faculty of Human Ecology, Universiti \\ Putra Malaysia, 43400 UPM, Malaysia \\ E-mail: *<s.mofrad@yahoo.com>, **<rohani_safri@yahoo.com> \\ ***Institute for Community \& Peace Studies, Universiti Putra Malaysia 43400 UPM, Malaysia \\ E-mail: drbas@ace.upm.edu.my
}

KEYWORDS Parenting. Young Children. Relationship. Attachment

\begin{abstract}
This study examined the likely direction of influence between perceived parental rearing and attachment type among first grade school children. Measures of perceived parental rearing and attachment type were administered to children through interview $(\mathrm{n}=120)$. The results revealed that securely attached children perceived their mothers as warmer than insecurely attached children. Ambivalently attached children perceived their mother as overprotective, anxious and less warm. More so, avoidantly attached children perceived their mothers as less warm and less protective. Further findings indicated that, ambivalently attached children perceived their mothers as overprotective and anxious than avoidant children. These results provide new insight into the direction of effects between attachment and perceived parental rearing during childhood. Future studies may consider moderating variables which may affect the relationship between perceived parental rearing and attachment style.
\end{abstract}

\section{INTRODUCTION}

Attachment theory is one of the most accepted theories used in explaining the relationship between parental rearing and child attachment type. The theory examined the nature and effects of parent-child relationships. Bowlby (1969) proposed that attachment arises from a behavioral system, which promote infant survival by motivating infants to seek proximity to protective individuals. According to Bowlby (1969) children develop different types of bonds with their caregivers such as secure or insecure attachment, this depends on the caregivers responsiveness and consistency (Thompson 2004). The security of attachment created within the interaction of the infant-caregiver during the first years of life influences a child in the way he/she interprets the social world and in the way he/ she comes to interact with other people (Ooi et al. 2006). Children with secure attachment have positive expectations regarding their parent's availability and responsiveness, whereas insecurely attached children have negative expectations (Cassidy and Shaver 1999).

On the other hand, parental rearing typically assumes a key role in the formation of attachments during early childhood (Bowlby 1973). Evidence from behavior genetics research, epidemiological, correlation and experimental studies reveal that the quality of parenting was the strongest risk factor to children's development (Collins et al. 2000). Specifically, lack of positive relationship with parents, insecure attachment, inadequate supervision and lack of involvement with children are strongly associated with children's increased risk for behavioral and emotional problems (Shaw et al. 1996). Conversely, when parents interact with their child in ways that are warm, responsive and reinforcing a positive relationship between parent and child was more likely to be established (Ainsworth 1979; Rutter 1979).

Bowlby (1977) determined two necessary and special characters of parenting, these are care and control. These characters are for desirable parenting and necessary for healthy parent- child interaction. Parker, Topling and Brown (1979) defined care and control as two separately continuous lines that specify desirable parenting in Bowlby's theoretical framework. Parker and colleagues (1979) showed that desirable parentings are characterized by high care and less control. The sense of good parental care defined by Bowlby (1969) includes satisfied interaction which expresses warmth, intimacy, love and continuity from mother to child. According to this perspective, individual differences in attachment styles reflect rules and strategies which children learn. These rules are learned through experiences of caregiver's responses to attachment related distress, but generalized to other distressing situations. 
Parker $(1979,1983)$ conceptualizes overprotective behaviors, which disallow a child's personal growth, autonomy, independence and care as related to the parent's ability to communicate, express affection, and promote closeness with the child. Care is assumed to have positive effects on parent-child relationship and child adjustment (Field 1996; Neal and Frick-Horbury 2001). Recent research (Yunger et al. 2005) has identified specific parental rearing as related to preoccupied and avoidant styles of attachment.

However, little attention has been paid to the relationship between parental rearing and child attachment, as examined in the present study. This study sought to identify correlates of perceived parental rearing style and attachment types. The study suggested that parental protection contributes to the child's use of ambivalent coping strategy. Children experience difficulty in becoming autonomous, possibly because their mothers do not allow them to be autonomous. With regard to avoidant coping styles, a lack of reliable parental support was the only significant parental predictor. This suggests that children avoid their mothers if they do not provide them with the necessary level of safety and security that they require. The main purpose of the study was to explore the possibility that there are meaningful associations between children's attachment styles and the perception of their mothers' behaviors. The authors tried to expand the conceptualization of attachment in young children. It was hypothesized that children's attachment types influence the perceptions of their mothers rearing. Avoidant children are expected to increase the perceptions of their parents as rejective, low in monitoring and overprotective. It was also predicted that ambivalently attached children will see their mothers as increasingly overprotective and high in anxiety.

\section{METHODOLOGY}

\section{Sample and Procedure}

Respondents were 120 normal children (54 boys; 65 girls) with a mean age of 7 years. All children were randomly selected from first grade elementary schools in Bushehr, Iran. Attachment Questionnaire for Children (AQC) was used in assessing attachment types. The children were classified based on their attachment type. In total the study assessed three attachment strategies, which comprise ambivalent, avoidant, and secure attachment. The Egna Minnen av Barndoms Uppforstran (EMBU-C) assessed perceived parental rearing. Children answered questions regarding behaviors demonstrated by their mothers in particular situations. Specifically, these scales assessed children's perceptions of parental warmth, overprotection, anxiousness and rejection. All children interviewed completed the measures individually in a quiet room at their school. Also, the children were encouraged to ask questions and assured that their response will remain anonymous.

After establishing that all variables were normally distributed, association between parental rearing and child attachment were explored. The data analysis continued with the calculation of ANOVA and regression analyses to explore the effect of child attachment types on perceived parental rearing styles. In the regression analyses, child attachment (i.e., a dummy variable with $0=$ secure attachment and $1=$ avoidant and ambivalent attachment) served as the predictor variables, while parental rearing styles served as the dependent variables. The magnitudes of the correlations were considered in addition to their statistical significance. Correlation coefficients of 0 to . 3 were consider.ed to be of small magnitude, whereas correlation coefficients of .4 to .7 were considered to be of moderate magnitude, and correlation coefficients of .8 or greater were considered to be of high magnitude.

\section{Measures}

The Egna Minnen av Barndoms Uppforstran (EMBU_C): The EMBU_C developed by Castro et al. (1993) and revised by Gruner et al. (1999) in an attempt to include parental anxiousness. The EMBU-C is an inventory for assessing memories of parental rearing, it focuses on children report. It consists of 40 items that include four subscales: emotional warmth (e.g. your mother likes you just the way you are), rejection (e.g., your mother treats you unfairly), overprotection (e.g., your mother wants you to reveal your secrets to her), and anxious rearing (e.g. your mother worries about you doing dangerous things). Each item was scored on a 4-point Likert-scale (1: No, never, 2: Yes, but seldom, 3: Yes, often, 4: Yes, most of the time). Gruner 
et al. (1999) found tentative evidence for the differential validity of the four parental rearing style of the EMBU-C. Many studies suggested that the EMBU-C can be considered a suitable instrument for children between 7-13 years (Markus et al. 2003; Muris et al. 2004; Brown and Whiteside 2008). In this study, the EMBU$\mathrm{C}$ was scored on four dimensions: warmth, overprotection, rejection and anxiousness. Reliability coefficients were calculated for each of the instruments utilized, including the subscales of parental rearing scales. Internal consistency for EMBU_C was 0.90. The subscales for warmth, over protection, rejection and anxiousness were $0.97,0.83,0.83$, and 0.97 respectively.

Attachment Questionnaire- Child version (AQC): The AQC (Muris et al. 2000) is an agedownward adaptation of Hazan and Shaver (1987) instrument for measuring attachment patterns in adults. The AQC was based on the assumption that attachment to a considerable extent defines affectionate relationships. Respondents determined that each item fits their characteristic style in their relationships.

The AQC consists of three descriptions that correspond with three basic patterns of attachment: 1- "I find it easy to become close friends with other children. I trust them and I am comfortable depending on them. I do not worry about being abandoned or about another child getting too close friends with me" (Secure attachment), 2- "I am uncomfortable to be close friends with other children. I find it difficult to trust them completely and difficult to depend on them. I get nervous when another child wants to become close friends with me. Friends often come more close to me than I want them to" (Avoidant attachment), 3- "I often find that other children do not want to get as close as I would like them to be. I am often worried that my best friend doesn't really like me and wants to end our friendship. I prefer to do everything together with my best friend; however, this desire sometimes scares other children away" (Ambivalent attachment). A previous study provided support for the validity of the AQC (Muris et al. 2000).

In this study, these three questions were reformed into 11 small sentences to make the options intelligible and easy to understand for 7 years old children. For example, the first question was divided into four questions (e.g., I find it easy to become close friends with other children. I trust them and I am comfortable depending on them. I do not worry about being abandoned by other children. I do not worry about other children getting too close friends with me). The second into four questions (e.g., I am uncomfortable to be close friends with other children. I find it difficult to trust other children completely, and difficult to depend on them. I get nervous when another child wants to become close friends with me. Friends often come more close to me than I want them to). And the last question into three questions (e.g., I often find that other children do not want to get as close as I would like them to be. I am often worried that my best friend doesn't really like me and wants to end our friendship. I prefer to do everything together with my best friend. However, this desire sometimes scares other children away).

The eleven items measured three attachment scales. The degree to which one feels comfortable with closeness and intimacy (secure), one's tendency to trust and depend on others to be responsive when needed (avoidant), and anxiety about abandonment or despise (ambivalent). In the present study, the scales yielded high internal consistency of .98; .93; .98 respectively for secure, avoidant and ambivalent attachment.

\section{RESULTS}

The result in table 1 represents the frequency of participants based on parental rearing and child attachment types. Based on the table, $48 \%$ of the children were secure, $17 \%$ was avoidant and 35\% was ambivalently attached. Further analysis revealed that securely attached children perceived their mothers as warm (37\%) than insecurely attached children. Also, ambivalently attached children perceived their mothers as overprotective (13\%) anxious (16\%) and less warm (4\%). More so, avoidantly attached children perceived their mothers as less warmth (.8\%) and less protective (7\%). There was a surprising result that $1 \%$ of avoidant children and none of

Table 1: Frequency of the children in regard to perceived parental rearing and attachment $(\mathbf{n}=120)$.

\begin{tabular}{lcc}
\hline & Frequency & Percent \\
\hline Parental warmth & 44 & 36.7 \\
Parental overprotection & 35 & 29.2 \\
Parental rejection & 4 & 3.3 \\
Parental anxious & 37 & 30.8 \\
Secure & 58 & 48.3 \\
Avoidant & 20 & 16.7 \\
Ambivalent & 42 & 35.0 \\
\hline
\end{tabular}


Table 2: Mean, Standard Deviation and Correlation coefficients of variables

\begin{tabular}{|c|c|c|c|c|c|c|c|c|c|}
\hline & Mean & S. D & 1 & 2 & 3 & 4 & 5 & 6 & 7 \\
\hline 1) Warmth & 25.3 & 9.01 & 1.000 & & & & & & \\
\hline 2) Overprotection & 29.6 & 4.74 & $-0.630^{* *}$ & 1.000 & & & & & \\
\hline 3) Rejection & 13.5 & 2.65 & $-0.366^{* *}$ & -0.064 & 1.000 & & & & \\
\hline 4) Anxious & 26.9 & 8.87 & $-0.825^{* *}$ & $0.862^{* *}$ & 0.157 & 1.000 & & & \\
\hline 5) Secure & 30.4 & 9.33 & $0.642^{* *}$ & $-0.453^{* *}$ & $-0.219^{*}$ & $-0.611^{* *}$ & 1.000 & & \\
\hline 6) Avoidant & 18.9 & 13.42 & $-0.567^{* *}$ & $0.301^{* *}$ & $0.186^{*}$ & $0.412^{* *}$ & $-0.746^{* *}$ & 1.000 & \\
\hline 7) Ambivalent & 22.2 & 16.19 & $-0.536^{* *}$ & $0.465^{* *}$ & 0.106 & $0.592^{* *}$ & $-0.787^{* *}$ & $0.294^{* *}$ & 1.000 \\
\hline
\end{tabular}

**. Correlation is significant at the 0.01 level (2-tailed).

*. Correlation is significant at the 0.05 level (2-tailed).

ambivalent children described their mothers as rejective. As can be seen in figure 1, securely attached children perceived their mothers as warm and less rejective.

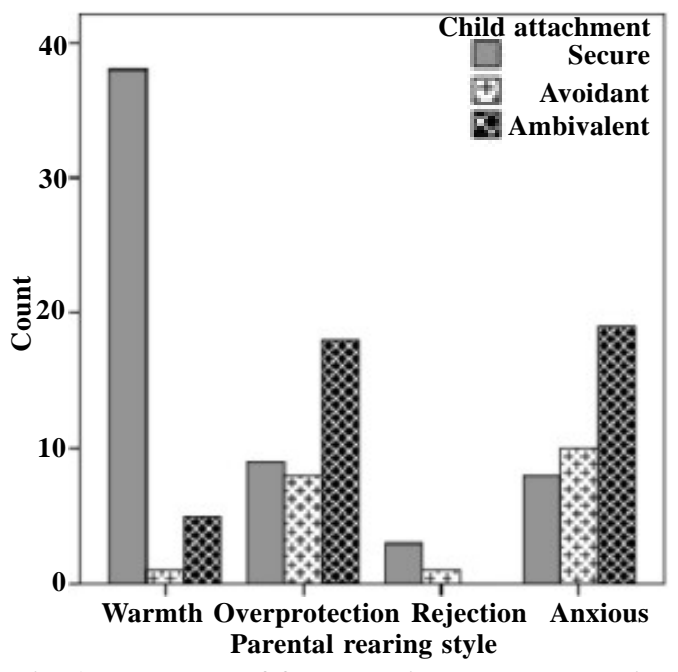

Fig. 1. Frequency of four perceived parental rearing and three child attachment types.

As depicted, secure attachment was positively correlated with parental warmth $(r=0.64, p<.01)$, and negatively correlated with other styles of parental rearing. The magnitudes of observed correlation were large, except in the case of parental rejection, which reached small magnitude.
More so, avoidant attachment was positively correlated with parental overprotection $(r=0.30$, $p<.01)$ and parental rejection $(r=0.19, p<.05)$, but negatively correlated with parental warmth $(r=0.57, p<.01)$. The magnitudes of observed correlation were moderate, except in the case of parental rejection. Furthermore, ambivalent attachment was positively correlated with parental anxiousness $(r=0.59, p<.01)$ and parental overprotection ( $r=0.47, p<.01)$, but negatively correlated with parental warmth $(r=0.54, p<.01)$. The study did not find significant correlation between ambivalent attachment and parental rejection. The magnitudes of observed correlation were moderate and large (see Table 2).

One-way ANOVA was conducted to explore the impact of child attachment on parental rearing styles. Results indicated that child attachment differed in terms of all perceived parental rearing styles, except parental rejection. Post-hoc comparisons using the Tukey HSD test indicated that the mean score of parental warmth, overprotection and anxious rearing for securely attached children was significantly different from both avoidant and ambivalent children. Precisely, securely attached children more often reported warm parenting less overprotection and anxious rearing as compared with avoidant and ambivalent children. Surprisingly, in terms of perceived rejection, children attachment types did not differ significantly from each other (see Table

Table 3: Mean and standard deviation of parental rearing styles for three child attachment types.

\begin{tabular}{|c|c|c|c|c|c|}
\hline Parental & $\begin{array}{l}\text { Secure } \\
(n=68) \\
M(S D)\end{array}$ & $\begin{array}{c}\text { Avoidant } \\
(n=18) \\
M(S D)\end{array}$ & $\begin{array}{c}\text { Ambivalent } \\
(n=34) \\
M(S D)\end{array}$ & $\begin{array}{l}\text { ANOVAs } \\
\text { (F values) }\end{array}$ & Post-hoc-test ${ }^{a}$ \\
\hline Warmth & $30.63(8.36)$ & $16.61(2.28)$ & $19.29(3.37)$ & $51.36 * *$ & Secure $>$ avoidant \\
\hline Overprotection & $27.65(4.91)$ & $31.28(4.21)$ & $32.76(1.88)$ & $18.73 * *$ & Secure $<$ avoidant \& ambivalent \\
\hline Rejection & $13.04(2.85)$ & $14.50(3.52)$ & $13.73(1.26)$ & 2.45 ns & \\
\hline Anxious & $22.06(8.68)$ & $31.61(4.92)$ & $34.23(1.65)$ & $40.25 * *$ & Secure $<$ avoidant \& ambivalent \\
\hline
\end{tabular}

${ }^{a}$ Evaluating the differences between secure, avoidant, and ambivalent attachment.

${ }^{*} \mathrm{p}<0.05, * * \mathrm{p}<0.005$, ns= non-significant 
3). To determine which child attachment type best predict the four parental rearing styles, four stepwise regression analyses were computed. All of the Rs, except perceived parental rejection, were statistically significant and moderate in size. Parental warmth was predictable from secure attachment $(\beta=.64)$, while secure attachment $\left(\mathrm{R}^{2}\right)$ explained $41 \%$ of the variation in parental warm (see Table 4).

Table 4: Stepwise multiple regression analysis for the prediction of parental warmth.

\begin{tabular}{lccc}
\hline Model & $B$ & $S E b$ & $\hat{a}$ \\
\hline Secure attachment & .620 & .068 & .642 \\
\hline Note $: \mathrm{n}=120, \mathrm{R}^{2}=.412, \mathrm{~A} \mathrm{R}^{2}=$ & $.407, \mathrm{~F}=82.66,(\mathrm{p}<.001)$.
\end{tabular}

A stepwise multiple regression analysis showed that the two variables of ambivalent and avoidant attachment explains only $25 \%$ of the variance in parental overprotection. This suggests that the model was mis-specified. The overall regression model was significant for both steps (see table 5). The significance of the F values was below .01, so the models for each step were significant. The most heavily weighted predictor variable was ambivalent attachment. Based on table 6, parental anxiousness was predicted from ambivalent attachment $(\beta=.29)$. The regression model was significant $(p<.01)$ and yielded an adjusted $\mathrm{R}^{2}$ value of .41 .

Table 5: Stepwise multiple regression analysis for the prediction of parental overprotection

\begin{tabular}{lccc}
\hline Model & $B$ & $S E b$ & $\hat{a}$ \\
\hline 1 & & & \\
Ambivalent & .136 & .024 & .465 \\
2 & & .025 & .412 \\
Ambivalent & .121 & .030 & .180 \\
Avoidant & .064 & .030
\end{tabular}

Note: $\mathrm{n}=120, \mathrm{R}^{2}=.22$ for model $1, \ddot{\mathrm{A}} \mathrm{R}^{2}=.23$ for model 2 , (ps $<.01)$.

Table 6: Stepwise multiple regression analysis for the prediction of parental anxious.

\begin{tabular}{lccc}
\hline Model & $B$ & $S E b$ & $\hat{a}$ \\
\hline Ambivalent & .161 & .063 & .293 \\
\hline
\end{tabular}

Note: $\mathrm{n}=120, \mathrm{R}^{2}=.406, \mathrm{Ä}^{2}=.395, \mathrm{~F}=39.93,(\mathrm{p}<.05)$.

\section{DISCUSSION}

The data gathered in the current study yielded a high number of significant correlations, many of which lend support to the proposed hypotheses. The first goal of the study was to deter- mine if child attachment predicts perceived parental rearing. It was hypothesized that avoidant children were expected to increase the perceptions of their parents as low warmth, low overprotection, and high rejection. Further, it was predicted that ambivalently attached children would see their parents as increasingly overprotective. This study was innovative in that it examined attachment during a specified period. The findings challenge traditional attachment views of the determinants of attachment in middle childhood. During middle childhood, children play a more active role in parentchild relationship than during infancy. Children are capable of evoking parenting behaviors and in some cases they may either intentionally or subconsciously create negatively biased profiles of their parents to confirm their insecure attachment style.

The results showed that secure attachment was positively correlated with parental warmth and negatively correlated with parental overprotection. Since secure attachment results from an early environment that provides for the emotional needs of the child (Bowlby 1988), it is logical that high care and low overprotection during childhood would result in a preference for secure attachment in a child's relationships. In order to develop secure attachment, children need to fulfill their curiosities by exploring further away from trusted caregivers, knowing that the caregiver will be there for them when they return. The finding of the current study was supported by Bowlby (1969) who proposed that a healthy relationship between parents and their children, foster secure attachment. Secure attachment as a result of parenting style encouraged children in the environment which increased secure feelings in the child. The fostering of autonomy which is the characteristic of parenting prepared the pathway for development and control of the environment for the child (Bowlby 1977).

Low scores for parental warmth or high scores for overprotection could run counter to the concept found in the study which revealed that avoidant and ambivalent attachment were positively correlated with parental overprotection and negatively correlated with parental warmth. The relationship between authoritative parenting and secure attachment has also been found by Neal and Frick-Horbury (2001). The current finding also, was consistent with a growing body of evidence (Field 1996; Yunger et al. 2005; Ooi et al. 2006) that attachment styles were associa- 
ted with parenting in ways that may foster secure versus insecure attachment orientations.

The current finding showed that there was no significant correlation between ambivalent attachment and parental rejection, which was in line with previous studies (Muris et al. 2000; Brown and Whiteside 2008). Unexpectedly, there was no significant difference between attachment types and parental rejection which was in contrast to previous studies (Cassidy 1994; Muris et al. 2000; Thompson 2004). The possible explanation was that the result may be due to the limited number of children (3\%) who reported perceived rejection behavior from their mother. Since insecure attachment was considered to result from the environment it does not support the optional development of the child (Bowlby 1988). It was interesting that only avoidant attachment was correlated with parental rejection. This result was in line with Muris et al. (2000) that found avoidant attachment as associated with perceived parental rejection. This finding maybe that child with avoidant attachment failed to report optimal care giving. For example Bartholomew (1993) reported that avoidant attachment was characterized by a denial of the need for close relationships. Perhaps respondent with avoidant attachment did not report optimal care giving because they did not feel close to their caregivers. It seems possible that the negative correlation between avoidant and parental warmth could be related to a dismissal of unpleasant memories. Yunger et al. (2005) have shown that avoidant mothers acted in a less warm and supportive manner toward their young children and felt more emotionally detached from them.

Interestingly, ambivalent attachment was the main predictor for perceived parental anxiousness. This finding is consistent with attachment research that demonstrated that children with ambivalent attachment perceive less emotional support (Cassidy 1994; Brown and Whiteside 2008). Individuals with ambivalent attachment have negative view of themselves. They like to have close relationships, but often do not because of their fear of rejection (Bartholomew 1993). In this case it is helpful to remember that trust may develop slowly in relationships. Bowlby (1977) proposed that a parent who failed to encourage exploration makes a child anxious, insecure, over-dependent and disposed to anxi- ety disorders under stressful situations. However, through overprotection the child automatically feels oppressed by others. It has been asserted that children develop attachment styles based on the parent's availability and responsiveness. However, we must take into consideration that, traditionally, attachment theory has been a theory for infants. Thus, it may not make great sense to expect the determinants of attachment to be the same in middle childhood as they are in infancy. On the other hand, it may be that perceived parental rearing style does influence attachment more broadly than this study depicted. For example, temperament constructs may play a role in attachment style that may act as moderators of children's responsiveness to insensitive and inept parental rearing (Cassidy 1994; Waters et al. 2000).

In summary, these results provided support for the hypothesis that avoidant children perceive their mothers as increasingly overprotective, less warm, and highly rejective. It was also found that ambivalently attached children significantly predicted perceptions of overprotection and anxious parental rearing. It has been suggested that children's immediate and later perceptions of parent-child interactions are influenced by their attachment representations (Feeney and Cassidy 2003). It was as if avoidant children know what constitutes a bad parent, and are increasingly seeing their parent as bad parents. It could also be that parents are actually withdrawing from avoidant children. Children may in fact be accurate in their negative perceptions of their parents. It has been suggested that parents of avoidant children may decrease their monitoring activities in order to avoid negative parentchild interactions (Laird et al. 2003).

Admittedly, this study has some limitations. One such limitation was that no true temperament measures were included in the scales. Future studies would benefit from including measures of temperament in order to examine possible moderating effects of temperament on the relationship between perceived parental rearing and attachment style. Another limitation is that all measures were self-reported. However, using self-reports provided us with children's perceptions of themselves and their relationships with their mothers. In addition, the independent and dependent variables were both measured by selfreports, therefore significant results may have been due to shared variance. 


\section{REFERENCES}

Ainsworth MS 1979. Infant-mother attachment. American Psychologist, 34: 932-937.

Bartholomew K 1993. From childhood to adult relationships: Attachment theory and research. In: SW Duck (Ed.): Understanding Relationship Processes 2: Learning about Relationships. London: Sage, pp. 3062.

Bowlby J 1973. Attachment and Loss: Separation (Vol. 2). New York: Basic Books.

Bowlby J 1977. The making and breaking of affectional bonds: A etiology and psychopathology in light of attachment theory. British Journal of Psychiatry, 130: 201-210.

Bowlby J 1988. A Secure Base: Parent-child Attachment and Healthy Human Development. New York: Basic Books, Inc.

Brown AM, Whiteside SP 2008. Relations among perceived parental rearing behaviors, attachment style, and worry in anxious children. Anxiety Disorders, 22: 263-272.

Cassidy J 1994. Emotion regulation: Influences of attachment relationships. In: NA Fox (Ed.): Emotion Regulation: Biological and Behavioral Considerations. Monographs of the Society for Research in Child Development, 59 (2-3): 228-249.

Cassidy J, Shaver PR 1999. Handbook of Attachment: Theory, Research, and Clinical Applications. New York: Guilford Press.

Castro J, Van-der-Ende J, Arrindell WA 1993. Explorating the feasibility of assessing perceived parental rearing styles in Spanish children with the EMBU. International Journal of Social Psychiatry, 39: 47-51.

Collins WA, Maccoby EE, Steinberg L, Hetherington EM, Bornstein MH 2000. Contemporary research on parenting: The case for nature and nurture. American Psychologist, 55: 218-232.

Feeney BC, Cassidy J 2003. Reconstructive memory related to adolescent-parent conflict interactions: The influence of attachment-related representations on immediate perceptions and changes in perceptions over time. Journal of Personality and Social Psychology, 85: $945-955$

Field T 1996. Attachment and separation young children. Annual Review of Psychology, 47: 541-561.

Gruner K, Muris P, Merckelbach H 1999. The relationship between anxious rearing behaviors and anxiety disorders symptomatology in normal children. Journal of Behavior Therapy and Experimental Psychiatry, 30: 27-35.

Hazan C, Shaver PR 1987. Romantic love conceptualized as an attachment process. Journal of Personality and Social Psychology, 59: 511-524.

Laird RD, Pettit GS, Bates JE, Dodge KA 2003. Parent's monitoring-relevant knowledge and adolescents' delinquent behavior: Evidence of correlated developmental change and reciprocal influences. Child Development, 74(3): 752-768.

Markus MT, Lindhout IE, Boer F, Hoogendijk THG, Arrindel WA 2003. Factors of perceived parental rearing styles: The EMBU-C examined in a sample of Dutch primary school children. Personality and Individual Differences, 34: 503-519.

Muris P, Meesters C, Merckelbach H, Hulsenbeck P 2000. Worry in children is related to percieved parental rearing and attachment. Behavioral Research and Therapy, 38: 487-497.

Muris P, Meesters C, Schouten E, Hoge E 2004. Effects of perceived control on relationship between perceived parental rearing behaviors and symptoms of anxiety and depression in nonclinical preadolescents. Journal of Youth and Adolescence, 33(1): 51-58.

Neal J, Frick-Horbury D 2001. The effects of parenting styles and childhood attachment patterns on intimate relationships. Journal of Instructional Psychology, 28(3): 178-181.

Ooi Y, Ang R, Fung D, Wong G, Cai Y 2006. The impact of parent-child attachment on aggression, social stress, and self esteem. School Psychology Internat-ional, 27(5): 552-566.

Parker G 1979. Reported parental characteristics of agoraphobics and social phobics. British Journal of Psychiatry, 135: 555-560.

Parker G 1983. Parental Overprotection: A Risk Factor in Psychosocial Development. New York: Grune \& Stratton.

Parker G, Topling H, Brown LB 1979. A Parental Bonding Instrument. British Journal of Medical Psychology, 52: $1-10$

Rutter M 1979. Protective factors in children's responses to stress and disadvantage. In: MW Kent, JE Roif (Eds.): Primary Prevention of Psychopathology, Volume III: Social Competence in Children. Hanover, NH: University of New England Press, pp. 49-74.

Shaw DS, Owens EB, Vondra JI, Keenan K, Winslow EB 1996. Early risk factor and pathways in the development of early disruptive behavior problems. Development and Psychopathology, 8: 679-699.

Thompson RA 2004. Development in the first years of life. In: EF Zigler, DG Singer, SJ Bishop-Josef (Eds.): Children's Play: The Roots of Reading. Washington, DC: National Center for Infants, Toddlers and Families, pp. 15-31.

Waters E, Hamilton CE, Weinfield NS 2000. The stability of attachment from infancy to adolescence and early adulthood: General introduction. Child Develo-pment, 71(3): 678-683.

Yunger JL, Corby BC, Perry DG 2005. Dimensions of attachment in middle childhood. In: KA Kernns, RA Richardson (Eds.): Attachment in Middle Childhoo. New York: Guilford, pp. 89-114. 